\title{
Mortality of Corophium volutator (Amphipoda) caused by infestation with Maritrema subdolum (Digenea, Microphallidae) — laboratory studies
}

\author{
Karin Meißner*, Andreas Bick \\ University of Rostock, Department of Zoology, Universitätsplatz 5, D-18051 Rostock, Germany
}

\begin{abstract}
The impact of Maritrema subdolum Jägerskiöld, 1908 on Corophium volutator Pallas, 1766 was examined under laboratory conditions. Adult specimens of $C$. volutator were placed in petri dishes and exposed to different numbers $(3,10,30,50,100,150,200)$ of recently emerged cercariae of the microphalid trematode $M$. subdolum. Addition of the same number of cercariae to the dishes was repeated every second day until the crustaceans died. The experiments revealed a strong negative correlation between the density of cercariae in the dish and the average survival times of $C$. volutator. Amphipods exposed to cercariae densities of 200 cercariae per $9.6 \mathrm{~cm}^{2}$ died after $1.6 \mathrm{~d}( \pm 0.5 \mathrm{SD})$ whereas specimens exposed to cercariae densities of 30 cercariae per $9.6 \mathrm{~cm}^{2}$ died after $35.8 \mathrm{~d}( \pm 7.1$ SD). All dead $C$. volutator were inspected for larval $M$. subdolum. Highest infestation intensities of approximately 80 larval $M$. subdolum were found in the test group to which 50 cercariae were added every second day. In other test groups, where $C$. volutator was exposed to either higher or lower cercariae densities, the specimens harboured fewer larval trematodes when they died. Not yet encysted metacercariae seemed to affect $C$. volutator in a more detrimental manner than encysted metacercariae. Changes in the behaviour of the infested crustaceans were observed during the experiments. Heavily infested specimens had problems with swimming and crawling in the normal way. All results are discussed in relation to field data. Mass mortality of $C$. volutator as a result of $M$. subdolum infestation seems to be an exceptional but conceivable occurrence in shallow water areas of the Baltic Sea.
\end{abstract}

KEY WORDS: Corophium volutator - Maritrema subdolum - Mortality - Digenea - Microphallidae Parasitism · Population dynamics

\section{INTRODUCTION}

In recent years the interest of marine ecologists has been focussing more and more on parasites as a biotic factor in the ecosystem. The impact of parasites has been considered in several conceptual models of community structure and dynamics (May 1983, Anderson 1991, Sousa 1991). Ecoparasitological aspects have been taken into account in explanations of fluctuations of population densities in the field (Lauckner 1984, Granovitch 1992, Bick 1994, Thomas et al. 1995). Special attention has been directed to digenetic trematodes, as their life cycle includes several hosts which have to co-occur in a biotope. In the case of the species

•E-mail: karin.meissner@biologie.uni-rostock.de
Maritrema subdolum Jägerskiöld, 1908, for instance, mud snails of the genus Hydrobia serve as primary intermediate hosts whereas several crustaceans (Amphipoda, Isopoda, Cirripedia) can be secondary intermediate hosts. Eventually, various sea birds serve as final hosts.

Mudsnails of the genus Hydrobia and the amphipod Corophium volutator Pallas, 1766 are common inhabitants of European coastal shores. It has by now become obvious that mass mortality of Hydrobia spp. and C. volutator coincides with heavy infestation by Maritrema subdolum and/or Microphallus claviformis (Brandes, 1888), another closely related microphallid trematode (Muus 1967, Lauckner 1987, Jensen \& Mouritsen 1992, Meißner \& Bick 1997). Lauckner (1987) and Mouritsen \& Jensen (1997) reported on enhanced 
mortality of $C$. volutator due to infestation by $M$. subdolum under laboratory conditions. Jensen et al. (1998) observed increased mortality within their experimental C. volutator population caused by infestation of $M$. claviformis. The impact of the parasites on the hosts and on the ecological system as a whole, however, is still poorly understood. For instance, little is known about the diversity of infestation effects on the host and quantitative aspects of parasite transmission.

The aim of the present study was to examine the impact, dependent on density, of Maritrema subdolum on Corophium volutator. The results of our investigations may give an answer to the question of whether potential densities of cercariae under natural conditions can cause mass mortality in $C$. volutator populations.

\section{MATERIALS AND METHODS}

Collection and storage of specimens. Specimens of Corophium volutator, Hydrobia ventrosa and $H$. ulvae were collected in a shallow water area of the Bay of Mecklenburg in the southern Baltic Sea in September 1997. The collected crustaceans were stored in a cooled incubator under $12 \mathrm{~h}$ light/12 h darkness at $19^{\circ} \mathrm{C}$ for $14 \mathrm{~d}$. The aerated aquaria were filled with filtered seawater $(12 \% \mathrm{~S}$, mean salinity in the biotope) and a layer of dried sediment from the biotope. The $C$. volutator were fed with the diatom Thalassiosira fluviatilis once a week. The collected Hydrobia spp. were placed in small petri-dishes with seawater under the same laboratory conditions. Every day the dishes were inspected for cercariae. The species were identified according to Reimer (1970) and Yamaguti (1975). The identified Maritrema subdolum-infected snails were maintained separately and fed with a few drops of a culture solution of the diatom T. fluviatilis every day to force the production of cercariae.

A random sample of Corophium volutator $(\mathrm{N}=36)$ was investigated to ascertain the infestation intensity before the experiments started. The mean load of preexperimental metacercarial cysts was about 11 . Metacercariae were identified as the species Maritrema subdolum and Levinseniella brachysoma Creplin, 1837 (Microphallidae), but the latter species was only seldom found.

Experimental design. Small petri dishes (area $=$ $\left.9.6 \mathrm{~cm}^{2}\right)$ were filled with $6 \mathrm{ml}$ of filtered seawater $(12 \%$ S) and a thin layer of dried sediment. 1 adult Corophium volutator (body length 4.5 to $5 \mathrm{~mm}$ ) and a certain number of recently emerged Maritrema subdolum cercariae $(3,10,30,50,100,150$ or 200 -corresponding to the experimental groups) were placed in every dish. There were at least 4 and at the most 10 replicates in each of these 7 experimental groups
Addition of the same number of cercariae to the dishes was repeated every second day to imitate natural conditions where cercariae emergence from the snails can occur within periods of several weeks in a highly temperature-dependent manner. From previous studies (Meißner \& Bick unpubl.) we knew that the life-span of the cercariae was approximately $20 \mathrm{~h}$. Thus, the crustaceans were allowed to recover for at least $1 \mathrm{~d}$ before they were exposed to the cercariae again. Dead crustaceans were measured, sexed and subsequently dissected under the microscope to ascertain the infestation intensity. A distinction was made between free-moving metacercariae of different sizes without any cyst wall, recently encysted metacercariae (with a cyst wall consisting of 1 thin layer only) and older metacercariae (with a cyst wall consisting of more than 1 layer).

All petri-dishes were inspected for dead Corophium volutator twice a day. The water in the dishes was renewed daily and the crustaceans were additionally fed with the diatom Thalassiosira fluviatilis. The temperature and light regime was the same as in the adaptation period

\section{RESULTS}

The exposure of Corophium volutator to different numbers of cercariae of the species Maritrema subdolum always led to the death of the amphipod during the period of the experiment. The experiments revealed a strong negative correlation between the density of $M$. subdolum-cercariae in the dish and the average survival times of $C$. volutator (Fig. 1). High

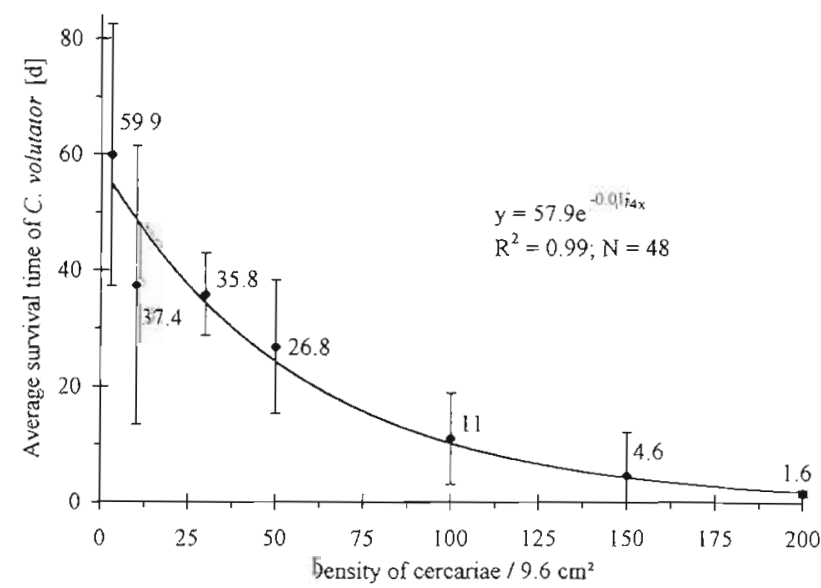

Fig. 1. Maritrema subdolum infecting Corophium volutator Regression between density of cercariae in the test dishes and average survival time $( \pm \mathrm{SD})$ of $C$. volutator. Addition of the same number of cercariae to the dishes was repeated every second day 


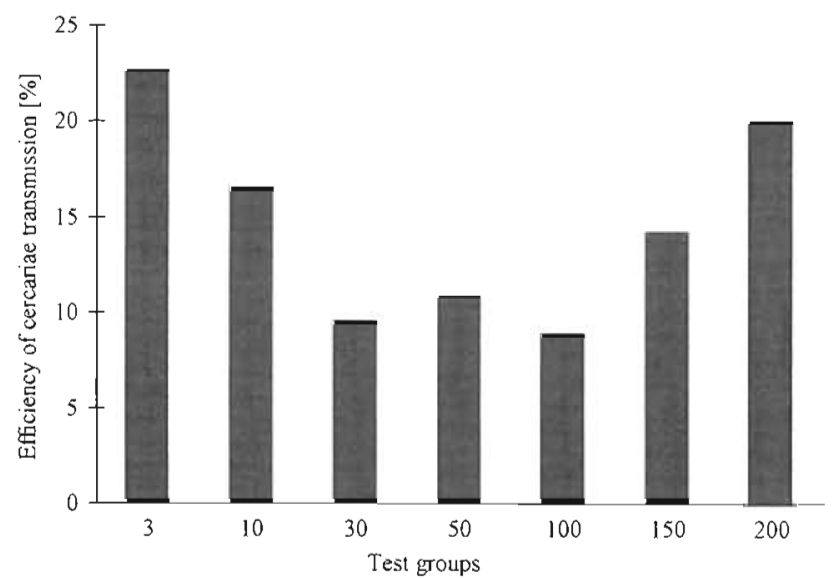

Fig. 2. Maritrema subdolum infecting Corophium volutator. Efficiency of cercariae transmission, expressed as the percentage of larval $M$. subdolum found in dead $C$. volutator in relation to the total amount of cercariae added during the experiment. (The mean load of 11 pre-experimental metacercariae-data from a random sample of $C$. volutator before the experiment started - was taken into account in the diagram)

densities of cercariae implied short survival times of $C$. volutator: when 200 or 150 cercariae were added every second day, the amphipod survived $1.6 \mathrm{~d}( \pm 0.5)$ and $4.6 \mathrm{~d}( \pm 7.5)$, respectively. Lower densities of cercariae enabled longer survival times: when 50, 30, 10 and 3 cercariae were added every second day, survival times from $26.8 \mathrm{~d}$ up to $59.9 \mathrm{~d}$ were found.

Distinct behavioural changes of Corophium volutator were observed during the experiment. At the beginning, specimens of all groups tried to avoid penetration by the cercariae. When the amphiphod came into contact with the cercariae, it started to bend and scoured its dorsum with its hindmost thoracopods. Later (after several exposures to cercariae) some specimens, especially from Groups 10 to 100, were no longer able to swim and crawl in the normal way and they sometimes tumbled. Additionally, they had difficulty bending and trying to get rid of the cercariae. These symptoms increased from exposure to exposure and finally $C$. volutator were unable to move and died. In contrast to this, specimens in Group 200 seemed to recover completely after exposure to cercariae. They later died more or less suddenly without any indication of unusual behaviour.

The percentage of cercariae found in dead Corophium volutator in relation to the total number of cercariae added during an experiment is a measure of the efficiency of cercariae transmission under laboratory conditions. This percentage was highest in experimental groups to which we added either only a few cercariae $(3,10)$ or very many $(150,200)$ (Fig. 2$)$. In Groups 30,50 and 100 approximately $10 \%$ of all cer-

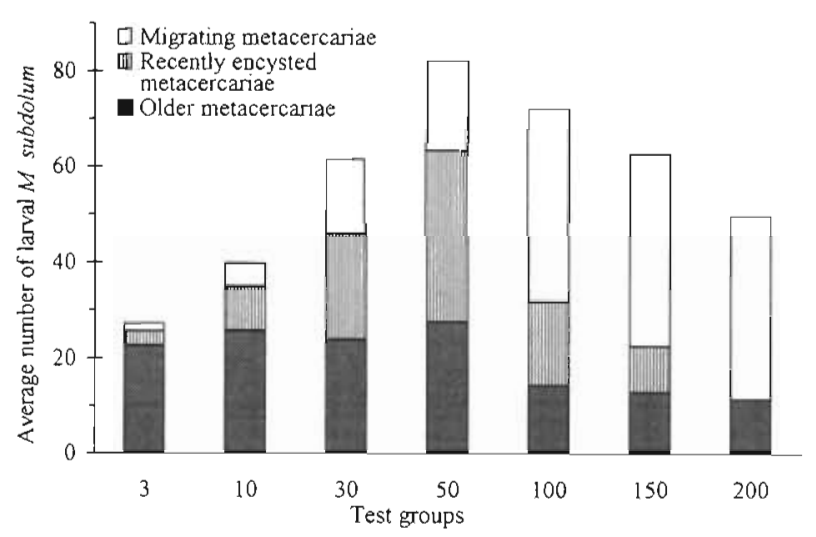

Fig. 3. Maritrema subdolum infecting Corophium volutator. Average number of the different developmental stages of larval $M$. subdolum found in dead $C$. volutator in the different test groups. (For SD see Table 1)

cariae were able to enter their hosts. The mean load of pre-experimental metacercariae was taken into account in the interpretation of the data.

Another point of investigation was to find out how many larval Maritrema subdolum can be accumulated by a single host before it dies. Most parasites on average were found in the group which was given 50 cercariae every second day in the dish (Fig. 3). However, the highest infestation intensities of all were found with single specimens from Groups 100 and 150 (Table 1). In Group 50 the mean intensity of infestation was around 80 when the Corophium volutator had died. With rising densities of cercariae from 3 up to 50 the mean infestation intensity increased, whereas with further increasing densities of cercariae up to 200 the average number of larval $M$. subdolum in $C$. volutator decreased (Fig. 3). What was conspicuous was the variation in the number of the different developmental stages of trematodes in the dead crustaceans among the experimental groups. In experimental Groups 3 to 50 , the amount of recently encysted and older metacercariae was much higher than that of migrating not-yetencysted metacercariae. However, the number of migrating metacercariae increased with rising densi-

Table 1. Corophium volutator. Infestation intensities including the 2 trematode species Maritrema subdolum and Levinseniella brachysoma

\begin{tabular}{|lcccccccc|}
\hline & \multicolumn{8}{c|}{ Test group } \\
& 3 & 10 & 30 & 50 & 100 & 150 & 200 \\
\hline Minimum & 19 & 14 & 44 & 45 & 30 & 19 & 30 \\
Maximum & 47 & 54 & 82 & 119 & 164 & 185 & 72 \\
Mean intensity & 28.6 & 41 & 63.75 & 82.8 & 72.8 & 63.6 & 51.6 \\
\pm SD & \pm 8.2 & \pm 20.7 & \pm 15.7 & \pm 30.2 & \pm 54.8 & \pm 68.4 & \pm 16.8 \\
& & & & & & & \\
\hline
\end{tabular}


ties of cercariae from 6.27 up to $25.2 \%$ within these groups. In the test Groups 100 to 200, the C. volutator contained mainly this type of metacercariae (56 to $77.2 \%$ ). It was remarkable that the average number of migrating metacercariae in C. volutator at the time of death was nearly identical (around 40) within these 3 groups. The number of recently encysted and older metacercariae decreased with rising cercaria densities. In the last group, no recently encysted metacercaria was found. Specimens of all experimental groups also harboured metacercariae of the species Levinseniella brachysoma, but just $2.34 \%$ of all larval trematodes found in $C$. volutator belonged to this species. Infestation with $L$. brachysoma took place before $C$. volutator had been collected in the field. For that reason infestation with $L$. brachysoma has been disregarded in the discussion.

\section{DISCUSSION}

The presence of the microphallid trematode Maritrema subdolum was identified as an important factor reducing the life-span of Corophium volutator under laboratory conditions. Particularly high densities of cercariae led to rapid death, but lower abundances of the parasites also shortened the life-span of the amphipod. A simple explanation for this could be the following: with rising densities more penetration attempts can be expected to occur and hence more successful ones. The possibility that loss of body fluid through the penetration holes accompanied by gill anaemia and osmoregulatory problems induces mortality in C. volutator is under discussion (Mouritsen \& Jensen 1997. Jensen et al. 1998). Thus, the specimens which were exposed to the highest cercaria densities died first. This explanation is not totally sufficient if we take the results of the parasitological examinations of the dead crustaceans into consideration. These results do not imply the same conclusion because the highest infestation intensities in dead C. volutator were not found in the test group with the highest cercaria densities. In addition, we must point out that $C$. volutator can survive in spite of the loss of both second antennae (field observations), in which case a greater loss of body fluid would be much more likely. Obviously other explanations must be found

The greatest number of trematodes was found in dead Corophium volutator from Group 50 (Fig. 3, Table 1). The specimens contained around 80 larval Maritrema subdolum on average, and a maximum of 119. Most of the larval trematodes ( 63 on average) were encysted metacercariae. Possibly this number of metacercariae presents a kind of upper limit which can be tolerated by the amphipod, and just a few new infestations or other stress factors cause the final death of the host. Nevertheless, in all other experimental groups the infestation intensity in $C$. volutator was lower but the crustaceans likewise died. It could be expected that lower infestation intensities would result in longer survival times. Indeed specimens from Groups 3 to 30 lived longer under experimental conditions than those from Group 50. On the other hand, $C$. volutator from Groups 100 to 200 died earlier despite lower infestation intensities. An explanation for this observation is provided by parasitological investigations of the dead $C$. volutator. Specimens from Groups 3 to 50 contained many more encysted metacercariae than not-yet-encysted migrating metacercariae, but the number of these migrating metacercariae predominated in comparison to the number of encysted ones in specimens from Groups 100 to 200. Obviously, migrating metacercariae affect $C$. volutator in a more detrimental manner than encysted metacercariae. All specimens from Groups 100 to 200 died after accumulating a number of around 40 not-yetencysted metacercariae. Therefore, we can assume that the death of $C$. volutator was due primarily to the high number of migrating metacercariae in these groups

The maturation of a cercaria which had already invaded the host to the next developmental stage, the metacercaria, takes at least $20 \mathrm{~h}$ and usually a few days longer (Meißner \& Bick unpubl.). A successive accumulation of cercariae allows the encystment of the migrating metacercariae and thus mainly encysted metacercariae were to be found in specimens from Groups 3 to 50 . This manner of infestation seems to be less detrimental because, although Corophium volutator in these groups had the highest infestation intensity, they had the longest life-spans as well. It is largely unknown how the different developmental stages of the trematodes affect the crustaceans. Possibly, encysted metacercariae exert a chiefly mechanical impact on the organs whereas migrating metacercariae cause damage by excretion of lytic enzymes or similar substances. Furthermore, effects on the immune system are conceivable (Benjamin \& James 1987).

The efficiency of transmission, expressed as the percentage of larval Maritrema subdolum found in dead Corophium volutator in relation to the total amount of cercariae added during the experiment, was highest in the groups with the lowest and with the highest density of cercariae under experimental conditions (Fig. 2). It is extremely difficult to find an adequate explanation for this phenomenon. Perhaps an answer can be found if we take observations of the behaviour of $C$. volutator into account. During the experiment, the crustaceans showed a peculiar behaviour designed to avoid penetration by cercariae. This behaviour was induced by 
contact with the cercariae. The number of contacts between cercariae and amphipods depends on the number of cercariae. This means that $C$. volutator from experimental Groups 3 and 10 came into contact with the trematodes only seldom in comparison to crustaceans exposed to higher densities. It is conceivable that one single penetrating cercaria did not stimulate the amphipod to show its special protective behaviour and prevention became more successful with an increasing number of repetitions. In the case of Groups 150 and 200, attempts by the cercariae to penetrate the crustaceans seemed to have occurred so frequently that there was no chance to avoid them at all.

The results of the laboratory studies must be discussed in relation to our field observations. First, the question of whether the densities of cercariae used in the experiments are relevant to natural conditions or not should be examined. Ecoparasitological studies were performed in the sampling area in 1996/1997. Mean abundances of Hydrobia ventrosa and $H$. ulvae, the first intermediate hosts of the trematodes, were 20000 ind. $\mathrm{m}^{-2}$ between May and September. The prevalence of the mud snails varied between 6 and $14 \%$; $15 \%$ of all trematode-infested snails were infested by Maritrema subdolum (Probst pers. comm.). Therefore, abundances of 180 to $420 \mathrm{M}$. subdolum-infected snails $\mathrm{m}^{-2}$ can be expected in the field. The emergence of cercariae is governed mainly by temperature (Rees 1948, Shostak \& Esch 1990). Cercarial production of a single Hydrobia sp. has been examined by several authors (Mouritsen \& Jensen 1997, Meißner \& Bick unpubl.). A total of 30 to 40 cercariae of the species $M$. subdolum seems to be a realistic amount for what can be produced by a snail at $19^{\circ} \mathrm{C}$ under normal conditions, but a maximum number of between 120 and 450 cercariae emerging per day has also been recorded. This level of production would result in densities from 5 to $198 \mathrm{M}$ subdolum cercariae $10 \mathrm{~cm}^{-2}$. The data indicate that densities of cercariae used in the laboratory studies lie absolutely within the range of potential densities which can be expected in the field. The collapse of intermediate host populations as a probable result of microphallid trematode infestation has been recorded several times (Muus 1967, Lauckner 1986, Jensen \& Mouritsen 1992, Thomas et al. 1995, Meißner \& Bick 1997). As the results of our investigations show, at least average densities of cercariae in the biotope cannot produce such collapses. Under field conditions one would expect that in the usual course of infestation Corophium volutator would pick up cercariae one by one. During our field study in 1994/1995 adult specimens collected from the field contained metacercariae almost without exception and relative densities of metacercariae were highest in the largest specimens of the population (Meißner \& Bick 1997). After having reached a high level of infestation these specimens obviously die as in the laboratory studies (Meißner \& Bick 1997). Enhanced mortality of adult individuals does not inevitably result in a population crash. During our field study the highest infestation intensities of adult specimens were observed a few weeks after the beginning of the reproduction period (Meißner \& Bick 1997). Hence, recruitment of the population is possible if the offspring achieves fertility and reproduction takes place. It should also be considered that the death of the secondary intermediate host cannot be in the interests of the parasite itself, as the death of $C$. volutator eventually means the death of the metacercaria. Therefore, the presence of stable intermediate host populations is essential for the completion of the parasite's life cycle. However, mass mortality of $C$. volutator is within the bounds of possibility, considering the maximum numbers of cercariae which emerged from a single Hydrobia sp. during our laboratory studies. In the biotope such unusually high cercarial production may occur in concert with certain weather conditions. A period of days with high temperatures could act as such a trigger. Mouritsen \& Jensen (1997) assumed that the population crash of $C$. volutator observed in 1990 was a result of unusually high temperatures. During the experiments, it was also observed that with rising infestation intensities the amphipods found it increasingly difficult to swim and crawl in the normal way. Mouritsen \& Jensen (1997) recorded increased surface activity in C. volutator exposed to parasites in comparison to control individuals. These changes of behaviour should transmute C. volutator harbouring larval trematodes into a preferred prey for predators. The advantage for the parasite is obvious. Additionally, there are other trematode species, Microphallus claviformis and Levinseniella brachysoma for example, which are suspected of harming C. volutator by infestation (Lauckner 1987, Jensen \& Mouritsen 1992, Jensen et al. 1998).

But benthic communities, including their parasites, are systems of high complexity. The occurrence of mass mortalities requires interplay between different abiotic and biotic factors. Further studies will be needed to understand how parasitism can affect population dynamics of marine invertebrates.

Acknowledgements. This study is part of a research project supported by the German Ministry of Education and Research under grant No. 03F0175A. We acknowledge the comments and suggestions of 3 anonymous reviewers.

\section{LITERATURE CITED}

Anderson RM (1991) Populations and infectious diseases: ecology or epidemiology? J Anim Ecol 60:1-50

Benjamin LR, James BL (1987) The responses of Ligia oceanica (L.) (Crustacea: Isopoda) to infection by Maritrema lin- 
guilla Jäg. 1908 and Microphallus similis (Jäg. 1900) (Digenea: Microphallidae) and to abiotic implants. J Invertebr Pathol 49:26-36

Bick A (1994) Corophium volutator (Corophiidae: Amphipoda) as an intermediate host of larval Digenea - an ecological analysis in a coastal region of the southern Baltic. Ophelia 40(1):27-36

Granovitch AI (1992) The effect of trematode infection on the population structure of Littorina saxatilis (Olivi) in the White Sea. In: Grahame H, Mill PF, Reid DG (eds) Proc 3rd Int Symp Littorinid Biology. The Malacological Society of London, p 255-263

Jensen KT, Mouritsen KN (1992) Mass mortality in two common soft-bottom invertebrates, Hydrobia ulvae and Corophium volutator - the possible role of trematodes. Helgol Meeresunters 46:329-339

Jensen T, Jensen KT, Mouritsen KN (1998) The influence of the trematode Microphallus claviformis on two congeneric intermediate host species (Corophium): infection characteristics and host survival. J Exp Mar Biol Ecol 227(1): $35-48$

Lauckner $G$ (1984) Impact of trematode parasitism on the fauna of a North Sea tidal fiat. Helgol Meeresunters 37: $185-199$

Lauckner G (1986) Ecological effects of larval trematode infestation on littoral marine invertebrate populations. Int J Parasitol 17(2):391-398

Lauckner G (1987) Effects of parasites on juvenile Wadden Sea invertebrates. In: Tougaard S, Asbirk S (eds) Proc 5th Int Wadden Sea Symp. The National Forest and Nature Agency \& The Museum of Fisheries and Shipping, Esbjerg, p 103-121

May RM (1983) Parasitic infections as regulators of animal populations. Am Sci 71:36-45

Editorial responsibility: Wolfgang Körting,

Hannover, Germany
Meißner K, Bick A (1997) Population dynamics and ecoparasitological surveys of Corophium volutator in coastal waters in the Bay of Mecklenburg (southern Baltic Sea) Dis Aquat Org 29:169-179

Mouritsen KN, Jensen KT (1997) Parasite transmission between soft bottom invertebrates: temperature mediated infection rates and mortality in Corophium. Mar Ecol Prog Ser 151:123-134

Muus B (1967) The fauna of Danish estuaries and lagoons. Distribution and ecology of dominating species in the shallow reaches of the mesohaline zone. Medd Komm Dan-Fiskeri Javundersogelser Serie: Fiskeri 5:1-316

Rees $G(1948)$ A study of the effect of light, temperature and salinity on the emergence of Cercaria purpurae LEBOUR from Nucella lapillus (L.). Parasitology 38:228-242

Reimer LW (1970) Digene Trematoden und Cestoden der Ostseefische als natürliche Fischmarken. Parasitol Schriftenr 20:1-144

Shostak AW, Esch GW (1990) Photocycle-dependent emergence by cercariae of Halipegus occidualis from Helisoma anceps, with special reference to cercarial emergence patterns as adaptations for transmission. J Parasitol 76(6): $790-795$

Sousa WP (1991) Can models of soft-sediment community structure be complete without parasites? Am Zool 31: $821-830$

Thomas F, Renaud T, Rousset F, Cezilly F, De Meeus T (1995) Differential mortality of two closely related host species induced by one parasite. Proc R Soc Lond B Biol Sci 260: $349-352$

Yamaguti S (1975) A synoptical review of life histories of digenetic trematodes of vertebrates with special reference to the morphology of their larval forms. Keigaku Publishing Co, Tokyo

Submitted: June 4, 1998; Accepted: November 1, 1998 Proofs received from author(s): December 18, 1998 